\title{
CONTROL OF ENERGY BALANCE USING THE ALTERATION OF BODY CONDITION IN DAIRY HERD HEALTH MANAGEMENT
}

\author{
C.-C. Gelfert, J.-A. Kupsch, R. Staufenbiel \\ Klinik für Klauentiere, Freie Universität D-14163 Berlin \\ mail: c_c_gelfert@yahoo.de
}

\begin{abstract}
Introduction
Herd health management in dairy cattle requires specific methods in order to detect imbalances in feeding management as early as possible and thereby to avoid economic losses. One important component in feeding management is energy. Energy balance and energy supply change throughout lactation. In the period around partus an oversupply or an undersupply both lead to detrimental consequences for the cow. The incidence of disease increases and production decreases. Therefore energy supply has to be checked periodically by examining the cow's condition. In herd health management two different methods have been developed: BCS-System and measuring backfatness by ultrasound. Monthly visits offer the possibility of using not only the absolute values but also the changing of cow's condition between two times of control. Beside information about the cow's actual condition a statement about the energy balance will be possible. This might be the better parameter to control energy supply of the herd during lactation.
\end{abstract}

\section{Material and method}

Periodical visits were made on eight dairy cattle farms in East Germany. The milk production ranged from 70001 (FCM) to $110001 / \mathrm{FCM}$ ), the herd size ranged from 150 to 1300 cattle. The farms were visited once a month. On the visits the condition of all cows between the sixth week ante partum and the sixth week post partum were determined by measuring the backfatness by ultrasound. The absolute values and the differences between two visits, converted to changes in backfatness per day, were correlated to stage of lactation, age of cow, milk yield, milk composition and fertility.

\section{Results}

Alterations in the cow's condition proved a more useful indicator than absolute values measured during particular stage of lactation. The change over from anbolism into katabolism ante partum depends on the age of the cow and the farm. These parameters also influence the extent of losses in backfatness and the point of time of the highest losses.

\section{Conclusions}

Periodical monitoring of body condition in dairy herd health management provides more information about energy balance when using the alteration of cow's condition instead of the absolute values. Because of the great variability among the farms visited further research is necessary. 